\title{
Clinicopathological study of hepatic mesenchymal hamartoma and undifferentiated embryonal sarcoma of the liver: a single center study from Iran
}

Parham Habibzadeh ${ }^{1}$, Mohaddese Ansari Asl2 ${ }^{2}$, Hamid Reza Foroutan ${ }^{3,4}$, Ali Bahador $^{4}$ and Mohammad Hossein Anbardar ${ }^{5^{*}}$

\begin{abstract}
Background: Undifferentiated embryonal sarcoma of liver (UESL) and hepatic mesenchymal hamartoma (HMH) are two rare entities which mainly affect the pediatric population. The aim of this investigation was to provide a comprehensive overview of the clinicopathologic characteristics of the patients diagnosed with these two conditions in a tertiary referral center in Iran.

Methods: In this retrospective study patients diagnosed with UESL or HMH between 2012 and 2020 were studied. A comprehensive histopathologic evaluation of the cases along with immunohistochemistry evaluation using a panel of antibodies was conducted. Furthermore, clinical, paraclinical, and treatment data and follow up information was collected.

Results: A total of 16 patients ( 8 UESL, $8 \mathrm{HMH}$ ) were studied in this investigation. Patients with UESL had a significantly $(p=0.002)$ higher age at diagnosis compared with those with HMH. Histologically, UESL cases were characterized by anaplastic cells with eosinophilic cytoplasm and bizarre nuclei and frequent atypical mitosis and spindling in a myxoid stroma while disordered arrangement of hepatic parenchyma, bile ducts, and primitive mesenchyme was seen in $\mathrm{HMH}$. Furthermore, small round cells and extramedullary hematopoiesis were seen in 2 UESL and $3 \mathrm{HMH}$ cases, respectively. Concurrent HMH was also seen in two UESL cases. Immunohistochemistry panel showed positive staining for Vimentin, Glypican-3, Desmin, CD56, CD10, and BCL2 in UESL cases and immunoreactivity for Vimentin, HepPar 1, Glypican-3, SMA, CD56, BCL2, and CD34 in various components of HMH.

Conclusions: In this study, the clinicopathologic features of UESL and HMH cases are presented. We also evaluated the utility of an immunohistochemistry panel in the diagnosis of these two rare entities and suggested novel markers. Our study corroborated the findings of previous investigations and expanded the clinicopathologic features of these two rare entities with diagnostic and potential therapeutic implications.
\end{abstract}

Keywords: Undifferentiated embryonal sarcoma of the liver, Hepatic mesenchymal hamartoma, Liver neoplasms, Immunohistochemistry, Pathology, surgical, CD56 antigen, Sarcoma, Pediatric liver tumors

\footnotetext{
* Correspondence: Anbardarm@sums.ac.ir

${ }^{5}$ Department of Pathology, Shiraz Medical School, Shiraz University of Medical Sciences, Shiraz, Iran

Full list of author information is available at the end of the article
}

(c) The Author(s). 2021 Open Access This article is licensed under a Creative Commons Attribution 4.0 International License, which permits use, sharing, adaptation, distribution and reproduction in any medium or format, as long as you give appropriate credit to the original author(s) and the source, provide a link to the Creative Commons licence, and indicate if changes were made. The images or other third party material in this article are included in the article's Creative Commons licence, unless indicated otherwise in a credit line to the material. If material is not included in the article's Creative Commons licence and your intended use is not permitted by statutory regulation or exceeds the permitted use, you will need to obtain permission directly from the copyright holder. To view a copy of this licence, visit http://creativecommons.org/licenses/by/4.0/ The Creative Commons Public Domain Dedication waiver (http://creativecommons.org/publicdomain/zero/1.0/) applies to the data made available in this article, unless otherwise stated in a credit line to the data. 


\section{Background}

Undifferentiated embryonal sarcoma of the liver (UESL) and hepatic mesenchymal hamartoma (HMH) are two rare pathologic entities that are primarily seen in the pediatric population [1]. UESL is a rare mesenchymal tumor accounting for $5-15 \%$ of liver malignancies in pediatrics [2-5]. On the other hand, $\mathrm{HMH}$, accounting for $8 \%$ of liver tumors in children, comprises the majority of pediatric benign liver tumors after infantile hemangioma $[1,6]$. UESL which is an aggressive tumor was first described in 1978 by Stocker and Ishak and is primarily diagnosed between 6 and 10 years of age without gender predominance $[7,8]$. However, $\mathrm{HMH}$ is mainly diagnosed in children of less than 2 years of age and shows a slight male predominance in this age group [9]. UESL usually arises from the right hepatic lobe with tumor size varying from $10 \mathrm{~cm}$ to $30 \mathrm{~cm}$ [5]. Similarly, $\mathrm{HMH}$ is primarily seen in the right hepatic lobe in children and can have various sizes of up to $30 \mathrm{~cm}$ in diameter $[9,10]$. Patients with UESL usually present with nonspecific symptoms including anorexia, abdominal pain, fever, and nausea with subsequent findings of cystic and solid components in imaging studies $[5,7,11$, 12]. Abdominal distention or mass is the most common clinical presentation of $\mathrm{HMH}$ which is usually seen as a multi-loculated cyst with a varying solid component on radiologic studies [10].

The underlying pathologic mechanisms playing a role in the development of UESL and HMH are unclear. However, different studies have proposed a number of potential mechanisms. Comparative genome hybridization $(\mathrm{CGH})$ studies of UESL have shown different patterns of chromosomal changes including losses of chromosome 9p, 11p, and 14 and gains of chromosome 1q, 5p, 6q, 8p, and 12q pointing to the potential role of chromosomal instability [13]. Genetic alterations leading to the ectopic activation of chromosome 19q microRNA cluster (C19MC) are found in $\mathrm{HMH}$ [14].

UESL is usually diagnosed based on the patient's age, tumor location, and an immunohistochemistry panel of undifferentiated markers including vimentin, desmin, $\alpha_{1}$ anti trypsin, CD10, and CD68 [15, 16]. However, $\mathrm{HMH}$ is usually diagnosed using clinical and histopathologic features alone [1]. Overall, as a result of the low incidence of these pathologic entities, the clinicopathological features of UESL and $\mathrm{MH}$ are limited to case series and case reports. Considering the paucity of reports from the Middle Eastern region, this study was conducted to investigate the clinical, histological, and immunohistochemical features in a series of patients with UESL and $\mathrm{HMH}$ in a single referral center from Iran.

\section{Materials and methods}

In this investigation, a retrospective evaluation of patients diagnosed with UESL and $\mathrm{HMH}$ at Shiraz University of Medical Sciences between 2012 and 2020 was conducted. The diagnosis was based on histopathological evaluation of tumor samples according to WHO classification of tumors of the digestive system. The specimens were obtained by surgical resection and were subsequently fixed in formalin and then embedded in paraffin. They were then stained using hematoxylin and eosin staining, periodic acid-Schiff (PAS) staining for UESL cases, and immunohistochemistical staining for all cases using the following antibodies: Vimentin (Máster Diagnóstica, rabbit monoclonal antibody, Clone SP20), HepPar 1 (Máster Diagnóstica, mouse monoclonal antibody, clone OCH1E5), Glypican 3 (Máster Diagnóstica, mouse monoclonal antibody, clone 1G12), Arginase-1 (Biocare Medical, rabbit monoclonal antibody, clone EP261), Ki67 (Máster Diagnóstica, rabbit monoclonal antibody, clone SP6), Desmin (Máster Diagnóstica, mouse monoclonal antibody, clone D33), SMA (Máster Diagnóstica, mouse monoclonal antibody, clone 1A4), CD56 (Máster Diagnóstica, rabbit monoclonal antibody, clone MRQ42), CD10 (Máster Diagnóstica, mouse monoclonal antibody, clone 56C6), CD68 (Máster Diagnóstica, mouse monoclonal antibody, clone KP-1), BCL2 (Máster Diagnóstica, rabbit monoclonal antibody, clone EP36), PD-L1 (Máster Diagnóstica, rabbit monoclonal antibody, clone CAL10), C-Kit (Máster Diagnóstica, rabbit monoclonal antibody, clone EP10), CD34 (Máster Diagnóstica, mouse monoclonal antibody, clone QBEnd/10). Appropriate positive and negative controls were used throughout the experiments. The immunohistochemistry slides were subsequently evaluated by a pathologist. In the event that less than $1 \%$ of the cells in a slide showed immunoreactivity, the case was considered negative. The positive cases were subsequently graded based on staining intensity as weak, intermediate, and strong. If more than half of the cells of interest were stained, the staining was considered diffuse. Otherwise, in cases with a staining percentage between 1 and 50\%, the staining was considered focal.

The following information was collected for both groups of the patients: patient age, sex, presenting symptoms, tumor location, significant laboratory findings. Furthermore, for patients diagnosed with UESL extrahepatic metastasis, recurrence, disease stage, and radiologic findings were collected. The treatments received by the patients with UESL and the disease outcome were also collected by contacting the family members. In addition, the gross and microscopic pathologic findings were documented for all the cases.

$R$ ver 4.0.2 (2020-06-22) was used for statistical analysis. Considering the small sample size of the study, 
continuous variables were reported as the median and interquartile range (IQR). Mann-Whitney $U$ test was used to compare the distribution of variables between two groups. The correlation between tumor size and age was assessed with Spearman's $\rho$. Kaplan-Meier survival analysis for the patients with UESL. A $p$ value $<0.05$ was considered statistically significant.

\section{Results}

The clinicopathologic characteristics and demographic data of the patients with UESL and HMH are presented in Tables 1 and 2, respectively.

Overall, there were 8 patients ( 3 males and 5 females) with UESL with a median age at diagnosis of 12.0 (IQR 4.6 to 13.3 ) years. In addition, 8 patients ( 5 males and 3 females) with $\mathrm{HMH}$ with a median age at diagnosis of 2.3 (IQR 1.4 to 2.5 ) years were identified. The age at diagnosis for those with UESL was significantly ( $p=$ 0.002) higher than those with $\mathrm{HMH}$. Abdominal pain was the most common $(8 / 8)$ presenting symptom in patients with UESL, followed by nausea/vomiting (3/8) and fever (2/8). Abdominal distention (4/8) and accidental identification of an abdominal mass by the patient's caregiver (3/8) were the most common complaints on initial presentation in patients with HMH. All the UESL and $\mathrm{HMH}$ patients identified had right liver lobe masses. Except for one patient with UESL, all of the UESL and $\mathrm{HMH}$ masses identified were unifocal. Initial laboratory abnormalities were more commonly observed in patients with UESL compared with those with MH. Anemia (4/8) and elevated hepatic transaminases levels (3/8) were seen in patients with UESL. Notably, elevated CA-125 levels were seen in one of the patients with UESL. Furthermore, one patient with $\mathrm{HMH}$ had elevated alphafetoprotein (AFP) levels. All patients diagnosed with $\mathrm{HMH}$ had undergone surgical resection of the liver mass and were alive after a median follow-up of 5.5 years without any complications. Most of the patients with UESL underwent gross tumor resection followed by adjuvant chemotherapy (7/8). Furthermore, 2/8 patients underwent radiation therapy as well. In patients with UESL, after a median follow-up time of 3 years, one patient had passed away and one of the patients was still under treatment due to recurrence. Overall, tumor recurrence was observed in two of the patients. No evidence of the disease after the treatment was detected among the other six patients with UESL. Patients with UESL had a mean survival time of 7.2 (95\% CI 5.7 to 8.7) years estimated by Kaplan-Meier survival analysis.

On gross examination, UESL was typically found as a well-defined mass with necrosis and hemorrhage. Gelatinous material in cases with myxoid change was also seen. The tumor size varied from $5.0 \mathrm{~cm}$ to $28.0 \mathrm{~cm}$ (median: $15.0 \mathrm{~cm}$, IQR $10.0 \mathrm{~cm}$ to $19.0 \mathrm{~cm}$ ) (Table 3).
There was no correlation between the tumor size and age at diagnosis (Spearman's $\rho=0.584, p=0.128$ ). Histological findings in UESL included anaplastic stellate to spindle-shaped or epithelioid tumor cells with poorly defined, light eosinophilic cytoplasm (Fig. 1A-B). Nuclei were found to be irregular and hyperchromatic with numerous mitotic figures (Fig. 1C). The anaplastic cells were arranged loosely or compactly in a usually myxoid stroma (Fig. 1D-E). Most of the cases had bizarre multinucleated giant cells with abundant cytoplasm and atypical nuclear features (Fig. 1F). Multiple variably-sized, periodic acid-Schiff diastase resistant-positive eosinophilic hyaline globules were also frequently seen in the cytoplasm or extracellular stroma (Fig. 1G-H). Of note, collections of small round cells were also seen in two of the cases (Fig. 1I). Furthermore, hemangiopericytomatous pattern was identified in another one of the cases (Fig. 1J). Furthermore, concurrent HMH was also identified in two of UESL cases (Fig. 1K) (Table 4).

On gross evaluation, $\mathrm{HMH}$ cases were characterized as a well-defined solitary mass without any evidence of hemorrhage except in one of the cases. The tumor size ranged from $8.0 \mathrm{~cm}$ to $20.0 \mathrm{~cm}$ (median: $13.0 \mathrm{~cm}$, IQR 11.4 $\mathrm{cm}$ to $15.5 \mathrm{~cm}$ ). No correlation between the tumor size and age at diagnosis was noticed (Spearman's $\rho=-0.331, p=$ $0.423)$. HMH was histologically characterized by the disordered arrangement of hepatic parenchyma, bile ducts, and mesenchyme consisting of spindled cells and myxoid stroma (Fig. 2A-C). Extramedullary hematopoiesis was detected in three of the cases. Furthermore, hemorrhage and severe hepatic steatosis were noted in one of the cases (Fig. 2D). Overall, 5 cases were predominantly cystic (Fig. 3A-B), while 3 cases were predominantly solid. (Table 2).

For immunohistochemical staining, we did not have access to the pathological specimens of two of the patients (HMH case 6 and UESL case 7) and therefore did not include them in the IHC studies. HMH associated with UESL in case 5 was included as a separate $\mathrm{HMH}$ case in the final analysis (Tables 5 and 6). A variable degree of Glypican 3 marker cytoplasmic staining with either strong or moderate immunoreactivity was found in UESL tumor cells. Diffuse strong cytoplasmic staining for this marker was also seen in four of HMH cases. Six UESL cases had strong cytoplasmic immunoreactivity for Desmin (3 diffuse, 3 focal) while five $\mathrm{HMH}$ cases showed strong cytoplasmic staining for this marker in the spindle cells (3 diffuse, 2 focal). Strong or moderate diffuse cytoplasmic staining for CD56 in all cases of UESL and also in the bile duct epithelium of $\mathrm{HMH}$ cases was observed. (Figs. 4 and 5).

\section{Discussion}

UESL and HMH are rare hepatic lesions primarily seen in the pediatric and early adult populations. In this investigation, we, for the first time, provide a 


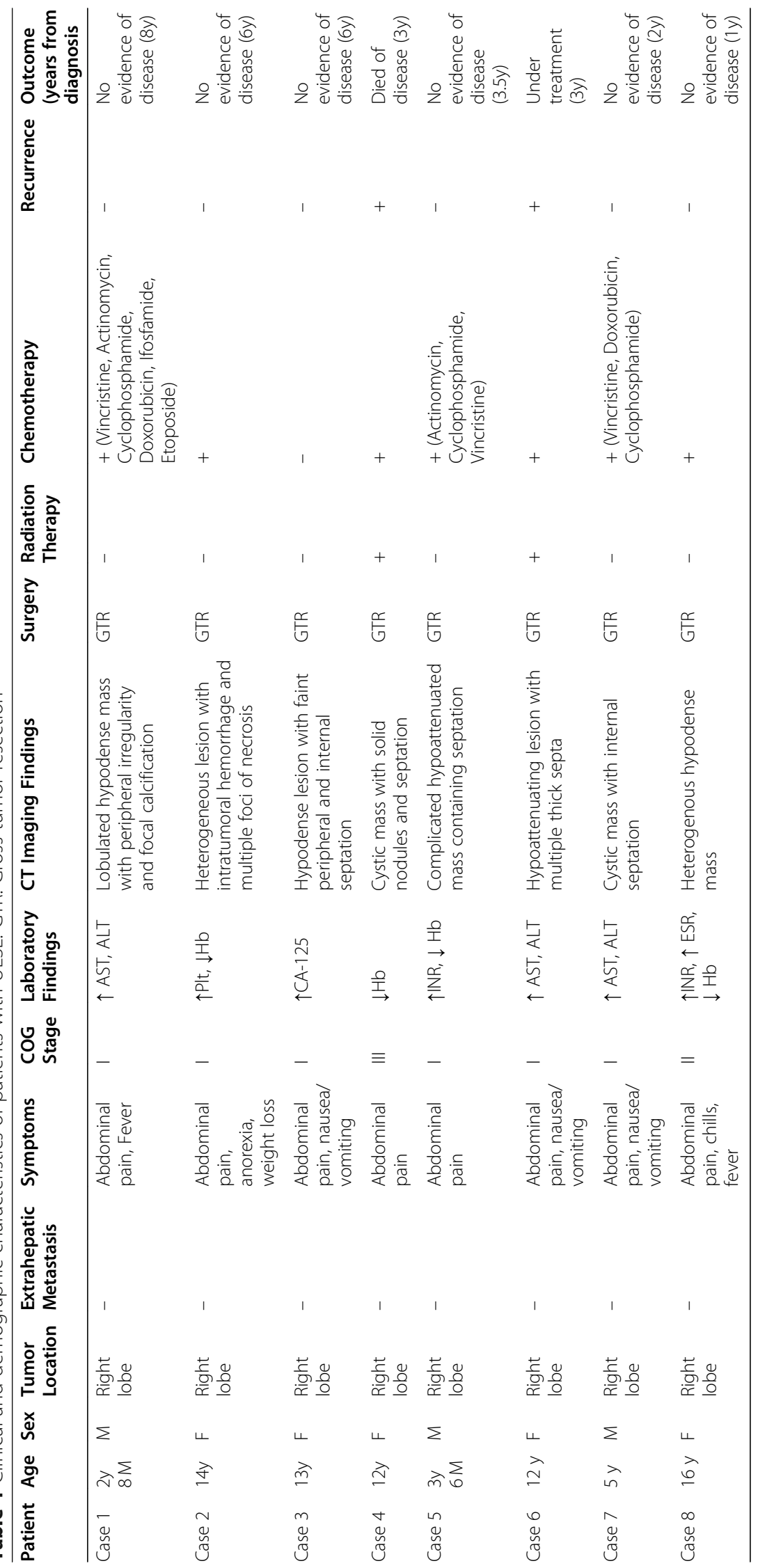


Table 2 Clinicopathologic characteristics and demographic features of patients with $\mathrm{HMH}$

\begin{tabular}{|c|c|c|c|c|c|c|c|c|c|}
\hline Patient & $\begin{array}{l}\text { Age } \\
(y)\end{array}$ & Sex & Symptoms & $\begin{array}{l}\text { Size } \\
(\mathrm{cm})\end{array}$ & Location & Focality & $\begin{array}{l}\text { Solid/ } \\
\text { Cystic }\end{array}$ & $\begin{array}{l}\text { Extramedullary } \\
\text { Hematopoiesis }\end{array}$ & Other Findings \\
\hline Case 1 & 2.5 & M & $\begin{array}{l}\text { Abdominal } \\
\text { Distention }\end{array}$ & 15 & $\begin{array}{l}\text { Right } \\
\text { Lobe }\end{array}$ & Unifocal & Solid & - & \\
\hline Case 2 & 2.5 & $\mathrm{~F}$ & $\begin{array}{l}\text { Abdominal } \\
\text { Distention }\end{array}$ & 12 & $\begin{array}{l}\text { Right } \\
\text { Lobe }\end{array}$ & Unifocal & Cystic & - & \\
\hline Case 3 & 1 & $\mathrm{~F}$ & Abdominal Mass & 9.5 & $\begin{array}{l}\text { Right } \\
\text { Lobe }\end{array}$ & Unifocal & Solid & - & \\
\hline Case 4 & 1.5 & M & $\begin{array}{l}\text { Abdominal Mass/ } \\
\text { Diarrhea }\end{array}$ & 12 & $\begin{array}{l}\text { Right } \\
\text { Lobe }\end{array}$ & Unifocal & Solid & + & \\
\hline Case 5 & 0.5 & M & $\begin{array}{l}\text { Abdominal } \\
\text { Distention }\end{array}$ & 17 & $\begin{array}{l}\text { Right } \\
\text { Lobe }\end{array}$ & Unifocal & Solid & + & $\begin{array}{l}\text { Hemorrhage/Severe Hepatic Steatosis/ } \\
\text { Elevated AFP (1125 ng/ml) }\end{array}$ \\
\hline Case 6 & 2.5 & M & Abdominal Mass & 14 & $\begin{array}{l}\text { Right } \\
\text { Lobe }\end{array}$ & Unifocal & Solid & + & \\
\hline Case 7 & 5 & M & $\begin{array}{l}\text { Abdominal Pain/ } \\
\text { Fever }\end{array}$ & 8 & $\begin{array}{l}\text { Right } \\
\text { Lobe }\end{array}$ & Unifocal & Cystic & - & \\
\hline Case 8 & 2 & $\mathrm{~F}$ & $\begin{array}{l}\text { Abdominal } \\
\text { Distention }\end{array}$ & 20 & $\begin{array}{l}\text { Right } \\
\text { Lobe }\end{array}$ & Unifocal & Cystic & - & \\
\hline
\end{tabular}

comprehensive clinicopathologic overview of these two entities in a case series from Iran. Overall, our findings show that patients with $\mathrm{HMH}$ are younger at presentation compared with those with UESL. Furthermore, both conditions had nonspecific initial clinical presentations with abdominal pain being present in all patients with UESL. These findings are in line with the previous investigations [6, 17]. Anemia and abnormal liver function tests were the most common findings in patients with UESL while patients with $\mathrm{HMH}$ had an overall normal baseline laboratory finding. Elevated tumor markers were observed in a number of patients; Elevated alpha fetoprotein levels in a $\mathrm{HMH}$ patient and an increased cancer antigen 125 (CA125) level was found in a patient with UESL. Elevated Erythropoietin levels have also been described in other patients with UESL which could be attributed to the mesenchymal origin of this tumor [18].

All of the patients with UESL had undergone gross surgical resection of the tumor followed by chemotherapy except for one of the patients who had not received chemotherapy. In addition, two of the patients with
UESL also received radiotherapy. In the past, the prognosis of liver sarcomas was poor overall. In the original report of 31 patients with UESL by Stocker and Ishak, only six patients were alive without any evidence of the disease [7]. Over the past couple of years, mounting evidence suggests that radical surgical resection of the tumor supplemented by adjuvant chemotherapy leads to an overall improvement in the survival of these patients [19]. Herein, we report encouraging results of following this protocol in patients with UESL. Six out of eight patients had no evidence of disease after a median followup time of 3 years. We were only able to retrieve the data regarding the chemotherapy regimen for three of the patients. However, based on our limited findings, all three of the patients who showed no evidence of disease on the latest follow up received vincristine and cyclophosphamide along with other chemotherapeutic agents. Treatment with vincristine, actinomycin-D, cyclophosphamide has been shown to be a successful therapeutic strategy in another report [20]. Notably, one of the patients had no evidence of disease 6 years after the

Table 3 Findings on gross examination of UESL cases

\begin{tabular}{|c|c|c|c|c|c|c|c|}
\hline Patient & Tumor Size (cm) & Focality & Well-defined/ill-defined & Cystic change & Hemorrhage & Necrosis & Myxoid Change \\
\hline Case 1 & 10 & Multifocal & Well-defined & - & + & $+(40 \%)$ & + \\
\hline Case 2 & 18 & Unifocal & Well-defined & + & + & $+(30 \%)$ & + \\
\hline Case 3 & 28 & Unifocal & Well-defined & + & + & $+(90 \%)$ & + \\
\hline Case 4 & 10 & Unifocal & Well-defined & + & + & $+(60 \%)$ & + \\
\hline Case 5 & 14 & Unifocal & Well-defined & - & + & $+(80 \%)$ & + \\
\hline Case 6 & 22 & Unifocal & Well-defined & + & + & $+(40 \%)$ & + \\
\hline Case 7 & 5 & Unifocal & Well-defined & + & + & $+(80 \%)$ & - \\
\hline Case 8 & 16 & Unifocal & Well-defined & + & + & $+(80 \%)$ & + \\
\hline
\end{tabular}




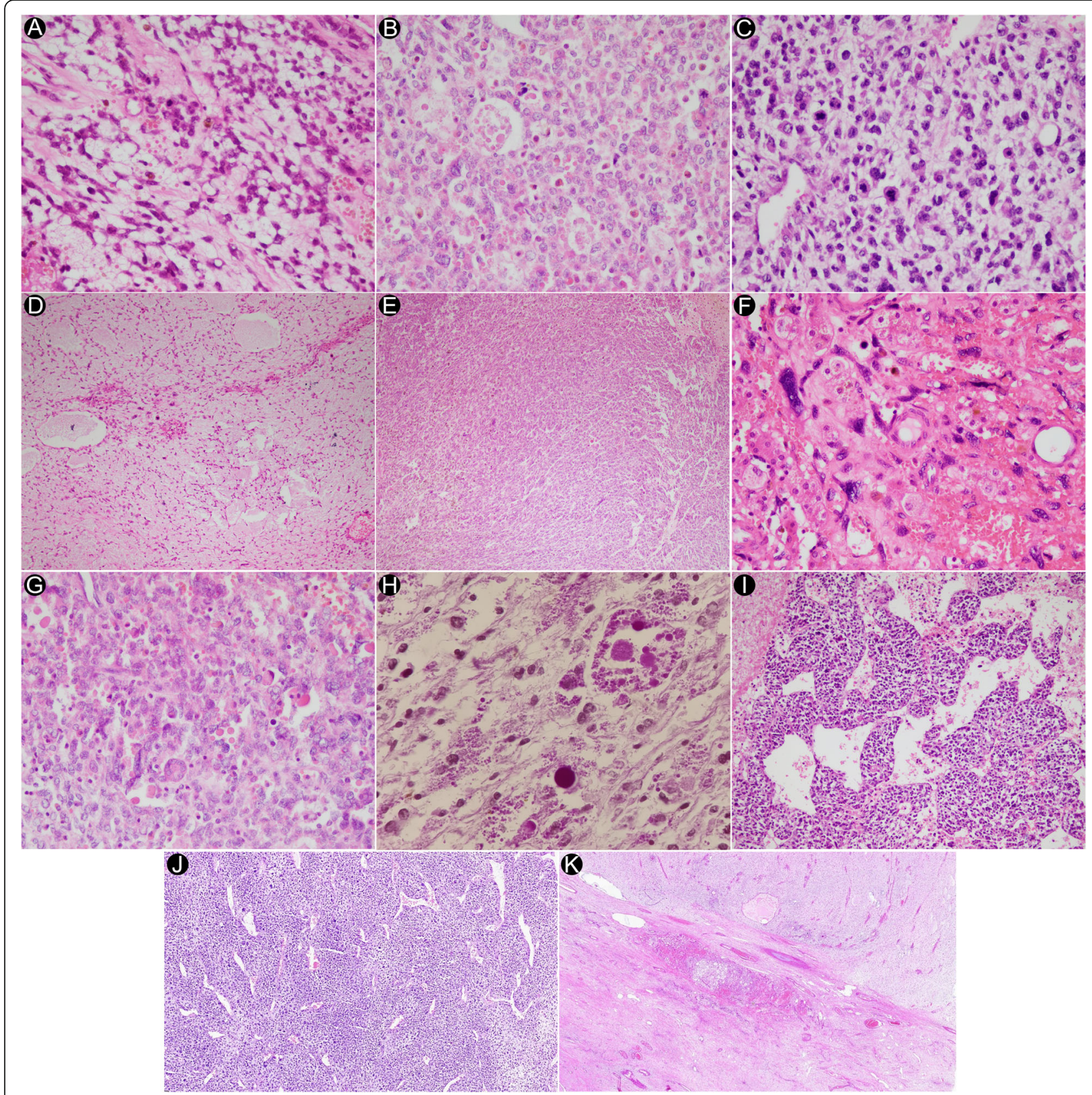

Fig. 1 Histopathologic findings in UESL cases. A Anaplastic stellate and spindle-shaped tumor cells with indistinct cytoplasmic border and light cytoplasm (Hematoxylin and Eosin, 400x). B Anaplastic epithelioid tumor cells with eosinophilic cytoplasm (Hematoxylin and Eosin, 400x). C Hyperchromatic nuclei with irregular nuclear border and multiple mitoses (Hematoxylin and Eosin, 400X). D Loosely arranged tumoral cells (Hematoxylin and Eosin, 100x). E Compactly arranged tumoral cells (Hematoxylin and Eosin, 100x). F Bizarre and multinucleated tumor cells with highly atypical nuclei (Hematoxylin and Eosin, 400x). G Multiple variably-sized eosinophilic hyaline globules (Hematoxylin and Eosin, 400x). H Periodic acid-Schiff diastase resistant-positive hyaline globules (400X). I Collections of small round cells (Hematoxylin and Eosin, 200x). J Hemangiopericytomatous pattern (Hematoxylin and Eosin, 40x). $\mathbf{K}$ Section from liver mass showing embryonal sarcoma at the top and mesenchymal hamartoma at the bottom (Hematoxylin and Eosin, 15x)

diagnosis only by gross tumor resection. This in turn highlights the paramount importance of surgical tumor resection in the treatment of this disorder.

On gross evaluation, all of the masses were located in the right hepatic lobe with variable sizes of up to $28 \mathrm{~cm}$.
UESL masses usually showed hemorrhage and cystic changes with variable degrees of necrosis while $\mathrm{HMH}$ cases presented with unifocal solid or cystic structures. Small round cells were seen on histologic evaluation of two UESL cases which could be an important finding if 


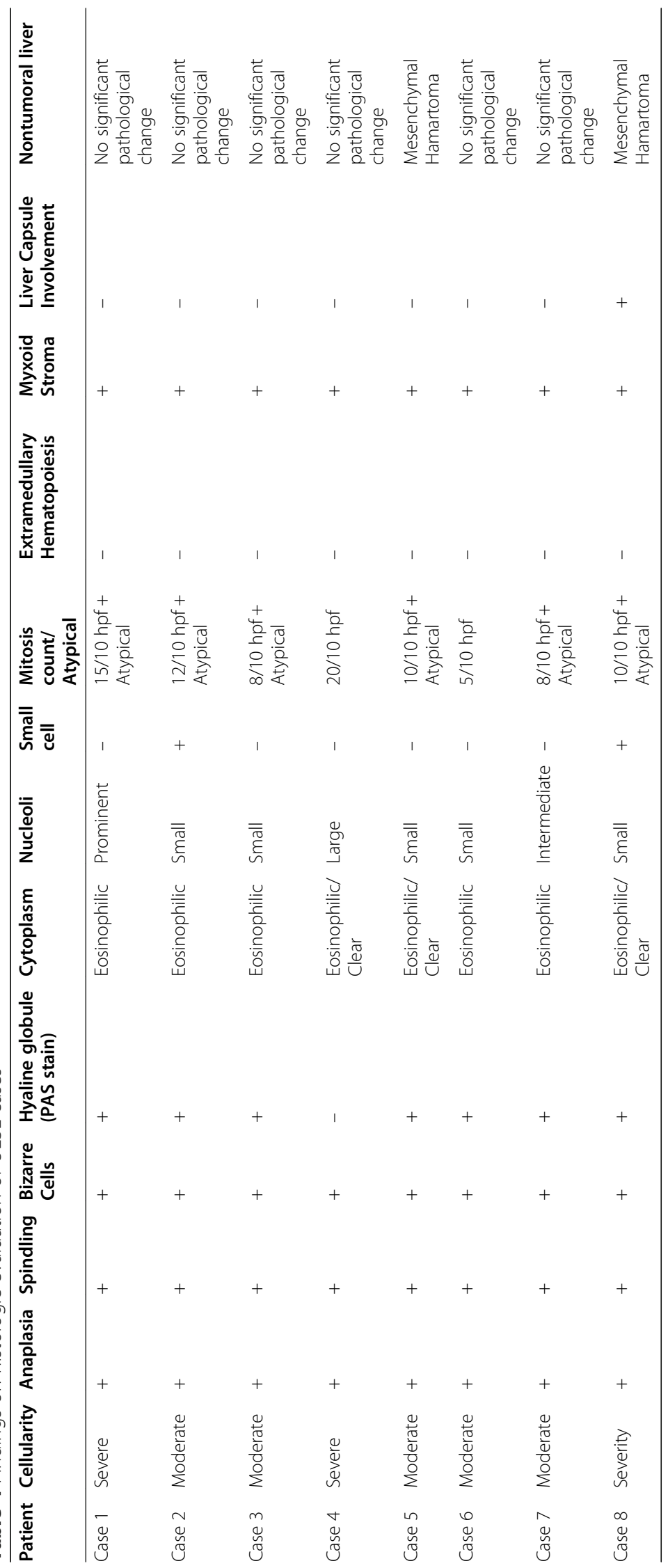




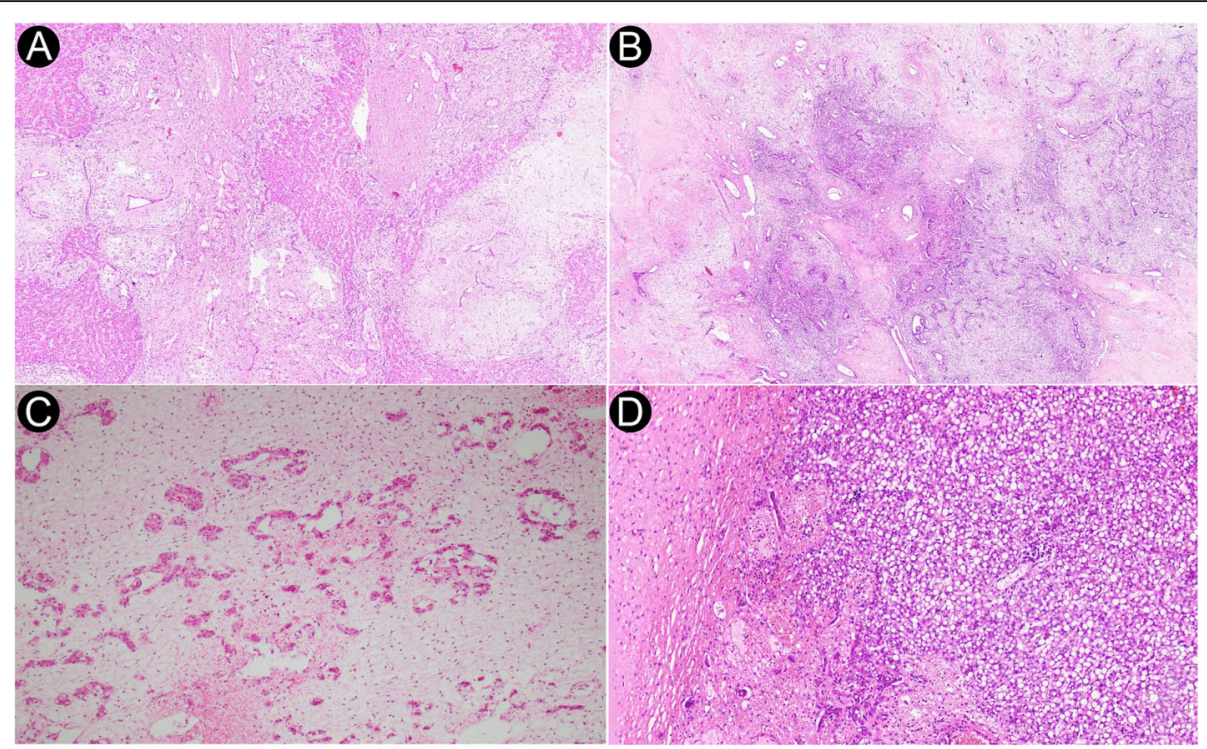

Fig. 2 Histopathologic findings in HMH cases. A Disordered arrangement of hepatic parenchyma, bile ducts, and spindled cells (Hematoxylin and Eosin, 40x). B Disordered arrangement of hepatic parenchyma, bile ducts, and spindled cells (Hematoxylin and Eosin, 20x). C Hepatic parenchyma in myxoid stroma (Hematoxylin and Eosin, 100x). D Severe hepatic steatosis (Hematoxylin and Eosin, 80x)

present in liver biopsies from these patients and can mimic other pathologies. In addition, severe hepatic steatosis seen in one of HMH cases points to potential molecular defects leading to deregulation of cellular energetics as seen in other liver disorders [21]. Furthermore, UESL was diagnosed in concurrence with $\mathrm{HMH}$ in two of the studied patients. This finding which has been also reported in a previous case series points to the potential malignant transformation of $\mathrm{HMH}$ in such patients [15].

The immunohistochemical phenotypes of UESL and $\mathrm{HMH}$ have only been investigated in a few studies so far. Overall, in three case series, positive immunostaining for vimentin and $\mathrm{Bcl}-2$ has been reported in most of the cases while positive staining for desmin, SMA, p53, pancytokeratin, Glypican-3, and calponin has been observed in some of the cases. Immunostaining for HepPar1, CD34, CD117 (C-kit), S100, HMB45, myogenin, ALK-1, and $\alpha$-fetoprotein were found to be negative in the primary tumor cells [22-24]. In addition, positive immunostaining for desmin, vimentin, SMA, Glypican-3, Hep $\operatorname{Par} 1$, and $\alpha$-fetoprotein in different components of $\mathrm{HMH}$ has been reported [24-26]. Our investigation highlighting immune-reactivity for CD56 in UESL and different components of $\mathrm{HMH}$ expands the findings of previous case series studies and corroborates their findings for other markers as well. Furthermore, our findings demonstrating the expression of Bcl-2 and CD34 in various components of $\mathrm{HMH}$ not only broadens its immunophenotypic spectrum but also provides fresh impetus for further investigations regarding the malignant transformation of $\mathrm{HMH}$ since both these two markers

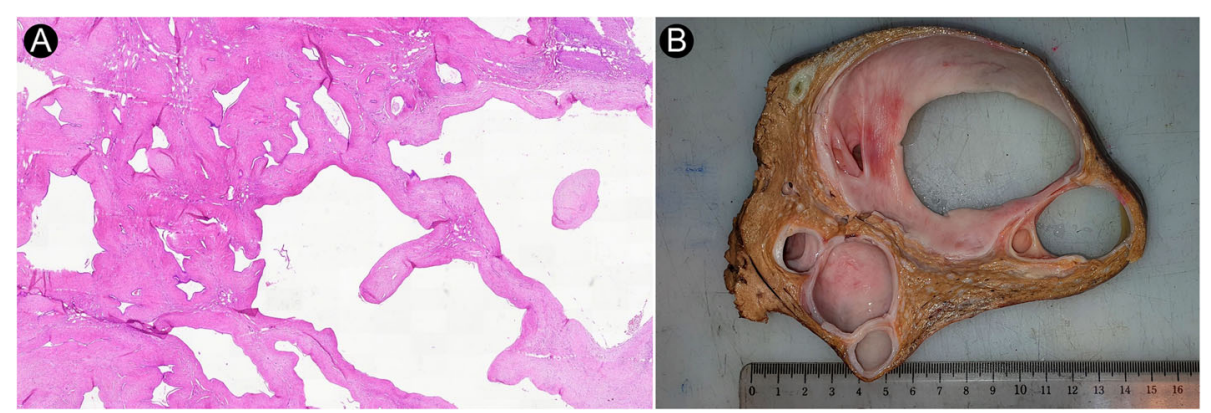

Fig. 3 Cystic change in $\mathrm{HMH}$. A Histopathologic section from HMH showing cystic change (Hematoxylin and Eosin, 20X). B Cut section of HMH with extensive cystic change 
Table 5 Immunohistochemistry findings in UESL cases. +++: strong staining intensity; ++: moderate staining intensity; +: weak staining intensity; f: focal staining

\begin{tabular}{|c|c|c|c|c|c|c|c|}
\hline & Case 1 & Case 2 & Case 3 & Case 4 & Case 5 & Case 6 & Case 8 \\
\hline Vimentin & +++ & $+++f$ & - & +++ & +++ & +++ & +++ \\
\hline HepPar1 & - & - & - & - & - & - & - \\
\hline Glypican 3 & $+++f$ & $+++f$ & ++ & +++ & +++ & $++f$ & ++ \\
\hline Arginase-1 & - & - & - & - & - & - & - \\
\hline Desmin & +++ & $+++f$ & $+f$ & $+++f$ & +++ & $+++f$ & +++ \\
\hline SMA & - & $+++f$ & - & $+++f$ & + & $+++f$ & $+++f$ \\
\hline CD56 & +++ & +++ & +++ & ++ & +++ & +++ & +++ \\
\hline CD10 & ++ & +++ & +++ & $++f$ & +++ & - & + \\
\hline CD68 & - & - & - & +++ & - & $+++f$ & - \\
\hline $\mathrm{BCL2}$ & +++ & - & + & + & + & +++ & + \\
\hline PD-L1 & - & - & - & - & - & - & - \\
\hline C-Kit & - & $+++f$ & - & - & - & - & $+f$ \\
\hline CD34 & - & - & - & - & - & - & - \\
\hline Ki67 & $80 \%$ & $40 \%$ & $15 \%$ & $80 \%$ & $60 \%$ & $15 \%$ & $90 \%$ \\
\hline
\end{tabular}

Table 6 Immunohistochemistry findings in HMH cases. +++: strong staining intensity; ++: moderate staining intensity; +: weak staining intensity; f: focal staining

\begin{tabular}{|c|c|c|c|c|c|c|c|c|c|c|c|c|c|c|c|}
\hline Case \# & Components & Vimentin & HepPar1 & $\begin{array}{l}\text { Glypican } \\
3\end{array}$ & $\begin{array}{l}\text { Arginase- } \\
1\end{array}$ & Desmin & SMA & CD56 & CD10 & CD68 & BCL2 & $\begin{array}{l}\text { PD- } \\
\text { L1 }\end{array}$ & $\begin{array}{l}\text { C- } \\
\text { Kit }\end{array}$ & CD34 & $\overline{\text { Ki67 }}$ \\
\hline \multirow[t]{3}{*}{ Case 1} & Spindle Cells & +++ & - & - & - & +++ & +++ & $++f$ & - & - & $+f$ & - & - & - & - \\
\hline & Hepatocytes & - & +++ & - & ++ & - & - & - & - & - & - & - & - & - & - \\
\hline & Bile ducts & - & - & - & - & - & - & +++ & - & - & ++ & - & - & - & - \\
\hline \multirow[t]{3}{*}{ Case2 } & Spindle Cells & +++ & - & - & - & $+++f$ & $+++f$ & $+f$ & - & - & $++f$ & - & - & +++ & - \\
\hline & Hepatocytes & - & +++ & - & +++ & - & - & - & - & - & - & - & - & - & - \\
\hline & Bile ducts & - & - & - & - & - & - & +++ & - & - & ++ & - & - & - & - \\
\hline \multirow[t]{3}{*}{ Case 3} & Spindle Cells & +++ & - & - & - & +++ & +++ & +++ & - & - & +++ & - & - & - & - \\
\hline & Hepatocytes & - & ++ & +++ & ++ & - & - & - & - & - & - & - & - & - & - \\
\hline & Bile ducts & +++ & - & - & - & - & - & +++ & - & - & +++ & - & - & - & - \\
\hline \multirow[t]{3}{*}{ Case 4} & Spindle Cells & +++ & - & - & - & +++ & +++ & ++ & - & - & ++ & - & - & - & - \\
\hline & Hepatocytes & - & +++ & +++ & +++ & - & - & - & - & - & - & - & - & - & - \\
\hline & Bile ducts & +++ & - & - & - & - & - & +++ & - & - & +++ & - & - & - & - \\
\hline \multirow[t]{3}{*}{ Case 5} & Spindle Cells & +++ & - & - & - & $+++f$ & ++ & + & - & - & - & - & - & - & - \\
\hline & Hepatocytes & - & +++ & +++ & - & - & - & - & - & - & - & - & - & - & - \\
\hline & Bile ducts & - & - & - & - & - & - & +++ & - & - & +++ & - & - & - & - \\
\hline \multirow[t]{3}{*}{ Case 7} & Spindle Cells & +++ & - & - & - & - & +++ & + & - & - & - & - & - & - & - \\
\hline & Hepatocytes & - & +++ & - & ++ & - & - & - & - & - & + & - & - & - & - \\
\hline & Bile ducts & - & - & - & - & - & - & +++ & - & - & +++ & - & - & - & - \\
\hline \multirow[t]{3}{*}{ Case 8} & Spindle Cells & +++ & - & - & - & - & $+++f$ & ++ & - & - & - & - & - & +++ & - \\
\hline & Hepatocytes & - & ++ & - & - & - & - & - & - & - & - & - & - & - & - \\
\hline & Bile ducts & - & - & - & - & - & - & +++ & - & - & +++ & - & - & - & - \\
\hline \multirow{3}{*}{$\begin{array}{l}\text { MH/UESL } \\
5\end{array}$} & Spindle Cells & +++ & - & - & - & - & +++ & - & - & - & - & - & - & +++ & - \\
\hline & Hepatocytes & - & +++ & - & ++ & - & - & - & - & - & - & - & - & - & - \\
\hline & Bile ducts & - & - & - & - & - & - & +++ & - & - & ++ & - & - & - & - \\
\hline
\end{tabular}




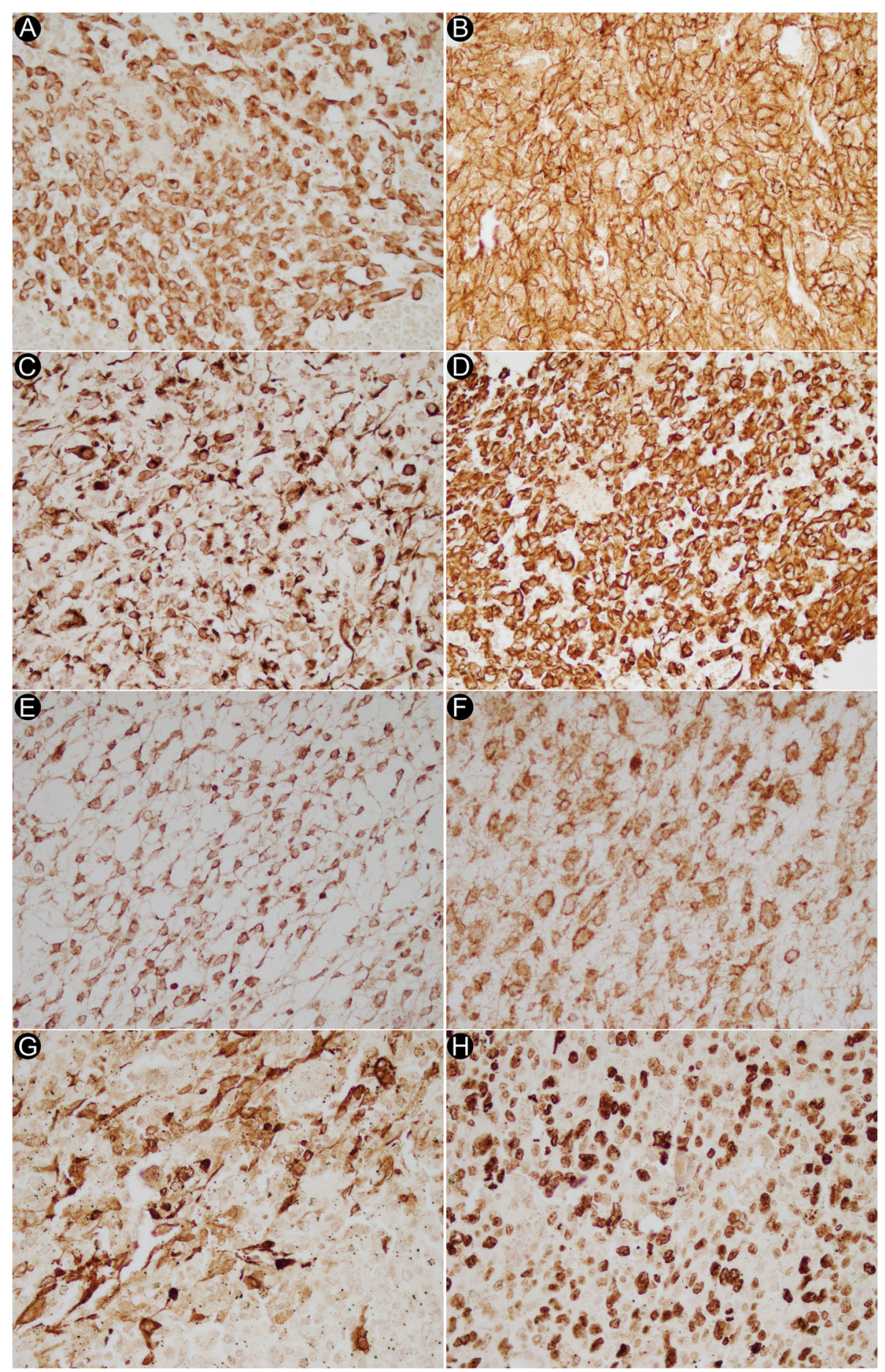

Fig. 4 Immunohistochemical findings in UESL. (A) Glypican 3 (B) CD56 (C) Desmin (D) Vimentin (E) BCL2 (F) CD10 (G) SMA (H) Ki67 (400X)

showed moderate to strong immunoreactivity in different components of the $\mathrm{HMH}$ case found in association with UESL. The development of UESL after incomplete excision of $\mathrm{HMH}$ reported in the literature corroborates this hypothesis [27, 28].
Absence of PD-L1 expression in all of the UESL cases investigated in this study points to the potential lack of efficacy of immune checkpoint inhibitors targeting this pathway as a therapeutic target in these patients [29]. However, positive staining for CD56 which is also 


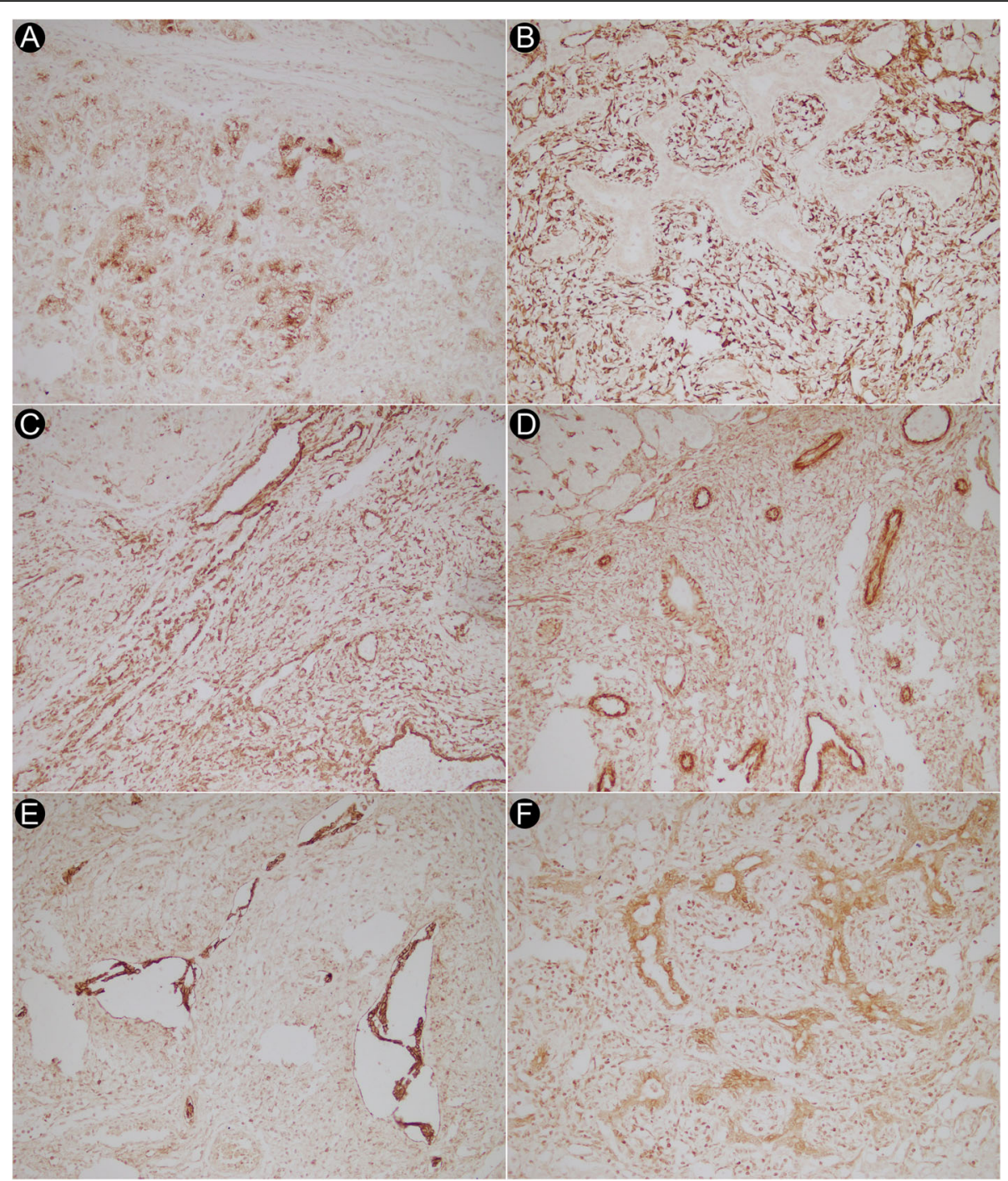

Fig. 5 Immunohistochemical findings in HMH. (A) Glypican 3 (B) Desmin (C) SMA (D) Vimentin (E) CD56 (F) BCL2 (200x)

reported in rhabdomyosarcoma and synovial sarcoma could have significant therapeutic implications in the management of UESL [30, 31]. CD56-chimeric antigen receptor T-cell therapy which has already shown promising results in the pre-clinical studies in other cancers could be used in the treatment of patients with a high CD56 expression in the tumor tissue who had shown disease recurrence with poor response to chemotherapy and radiotherapy (e.g. UESL case 6 in this study) [32].

The main differential diagnoses of UESL in the pediatric and adolescent population include hepatoblastoma, $\mathrm{HMH}$, embryonal rhabdomyosarcoma, hepatic angiosarcoma, and hepatocellular carcinoma [23, 33]. IHC staining could play a substantial role in accurate diagnosis particularly in situations where histopathologic clues are not helpful. Our study showing Glypican-3 expression in both UESL and HMH cases demonstrates that this marker cannot be used to differentiate the two from hepatocellular carcinoma and hepatoblastoma which have been shown to express this antigen [34, 35]. Nevertheless, our study showed absence of HepPar 1 and Arginase- 1 in all of the UESL cases highlighting the importance of this maker in differentiating UESL from hepatocellular carcinoma for which these two markers have been shown to display a sensitivity of 84.4 and $96.0 \%$, respectively [36]. Positive staining for skeletal muscle differentiation markers such as myoD1 and myogenin along with cross-striation are distinctive findings in rhabdomyosarcoma [37]. Furthermore, CD34 marker which was found to be negative in all of the cases in this investigation can be a very useful marker in the diagnosis of hepatic angiosarcoma which frequently stains positive for this marker [38]. Features such as anaplasia and high grade mitotic activity (strongly positive staining for 
ki-67) as observed in this study are useful diagnostic features to distinguish UESL from HMH.

In summary, this investigation reports the first case series of patients with UESL and HMH from Iran. Herein, we reported the clinicopathologic findings of sixteen patients from a single referral pediatric center. Although due to the rarity of these two pathologic entities we were not able to recruit a large number of patients in order to investigate the prognostic significance of different pathologic findings, we were able to identify significant histopathologic findings and novel IHC markers with diagnostic and therapeutic implications. Further investigations have to be conducted to shed light on the clinicopathologic and pathophysiologic basis of these two rare entities.

\section{Abbreviations}

UESL: Undifferentiated embryonal sarcoma of the liver; HMH: Hepatic mesenchymal hamartoma; PAS: Periodic Acid-Schiff; IQR: Interquartile range

\section{Acknowledgements}

The authors would like to thank the family members and the patients for their collaboration in this investigation. This study was conducted in partial fulfillment of the requirements for the M.D. degree of Shiraz University of Medical Sciences (Thesis \#18811).

\section{Authors' contributions}

$\mathrm{PH}$ prepared the first draft of the manuscript, was involved in the histopathologic evaluation of the cases and analyzed and interpreted the data. MAA did the data collection and contributed to the draft of the manuscript. HRF was involved in the clinical evaluation of the patients and revised the manuscript. $A B$ was involved in the clinical evaluation of the patients and revised the manuscript. MHA supervised and designed the study, revised the manuscript, carried out the histopathologic examination of the cases and interpreted the data. All authors read and approved the final manuscript.

\section{Funding}

This study was supported by Shiraz University of Medical Sciences ViceChancellor of Research grant (18811) awarded to MHA.

\section{Availability of data and materials}

All data generated or analyzed during this study are included in this published article.

\section{Declarations}

Ethics approval and consent to participate

This study was approved by Shiraz University of Medical Sciences Ethics Committee.

\section{Consent for publication}

Informed consent from the participants or their guardians was obtained.

\section{Competing interests}

The authors declare no competing interests.

\footnotetext{
Author details

'Persian BayanGene Research and Training Center, Shiraz University of Medical Sciences, Shiraz, Iran. ${ }^{2}$ Student Research Committee, Shiraz University of Medical Sciences, Shiraz, Iran. ${ }^{3}$ Laparoscopy Research Center, Shiraz University of Medical Sciences, Shiraz, Iran. ${ }^{4}$ Department of Pediatric Surgery, Nemazee Hospital, Shiraz University of Medical Sciences, Shiraz, Iran. ${ }^{5}$ Department of Pathology, Shiraz Medical School, Shiraz University of Medical Sciences, Shiraz, Iran.
}

Received: 23 February 2021 Accepted: 10 June 2021

Published online: 24 June 2021

\section{References}

1. Martins-Filho SN, Putra J. Hepatic mesenchymal hamartoma and undifferentiated embryonal sarcoma of the liver: a pathologic review. Hepat Oncol. 2020;7(2):HEP19.

2. Ismail H, Dembowska-Baginska B, Broniszczak D, Kalicinski P, Maruszewski $P$, Kluge $P$, et al. Treatment of undifferentiated embryonal sarcoma of the liver in children--single center experience. J Pediatr Surg. 2013;48(11):2202-6.

3. Lack EE, Schloo BL, Azumi N, Travis WD, Grier HE, Kozakewich HP. Undifferentiated (embryonal) sarcoma of the liver. Clinical and pathologic study of 16 cases with emphasis on immunohistochemical features. Am J Surg Pathol. 1991;15(1):1-16.

4. Sodhi KS, Bekhitt E, Rickert C. Paradoxical hepatic tumor: undifferentiated embryonal sarcoma of the liver. Indian J Radiol Imaging. 2010;20(1):69-71.

5. Wei ZG, Tang LF, Chen ZM, Tang HF, Li MJ. Childhood undifferentiated embryonal liver sarcoma: clinical features and immunohistochemistry analysis. J Pediatr Surg. 2008;43(10):1912-9.

6. Siddiqui MA, McKenna BJ. Hepatic mesenchymal hamartoma: a short review. Arch Pathol Lab Med. 2006;130(10):1567-9.

7. Stocker JT, Ishak KG. Undifferentiated (embryonal) sarcoma of the liver: report of 31 cases. Cancer. 1978;42(1):336-48.

8. Plant AS, Busuttil RW, Rana A, Nelson SD, Auerbach M, Federman NC. A single-institution retrospective cases series of childhood undifferentiated embryonal liver sarcoma (UELS): success of combined therapy and the use of orthotopic liver transplant. J Pediatr Hematol Oncol. 2013;35(6):451-5.

9. Stocker JT, Ishak KG. Mesenchymal hamartoma of the liver: report of 30 cases and review of the literature. Pediatr Pathol. 1983;1(3):245-67.

10. Stringer MD, Alizai NK. Mesenchymal hamartoma of the liver: a systematic review. J Pediatr Surg. 2005;40(11):1681-90.

11. Buetow PC, Buck JL, Pantongrag-Brown L, Marshall WH, Ros PR, Levine MS, et al. Undifferentiated (embryonal) sarcoma of the liver: pathologic basis of imaging findings in 28 cases. Radiology. 1997;203(3):779-83.

12. Chung EM, Lattin GE Jr, Cube R, Lewis RB, Marichal-Hernandez C, Shawhan $R$, et al. From the archives of the AFIP: pediatric liver masses: radiologicpathologic correlation. Part 2. Malignant tumors. Radiographics. 2011;31(2): 483-507.

13. Sowery $\mathrm{RD}$, Jensen $\mathrm{C}$, Morrison $\mathrm{KB}$, Horsman $\mathrm{DE}$, Sorensen PH, Webber EM. Comparative genomic hybridization detects multiple chromosomal amplifications and deletions in undifferentiated embryonal sarcoma of the liver. Cancer Genet Cytogenet. 2001;126(2):128-33.

14. Kapur RP, Berry JE, Tsuchiya KD, Opheim KE. Activation of the chromosome $19 q$ microRNA cluster in sporadic and androgenetic-biparental mosaicismassociated hepatic mesenchymal hamartoma. Pediatr Dev Pathol. 2014; 17(2):75-84

15. Shehata BM, Gupta NA, Katzenstein HM, Steelman CK, Wulkan ML, Gow KW et al. Undifferentiated embryonal sarcoma of the liver is associated with mesenchymal hamartoma and multiple chromosomal abnormalities: a review of eleven cases. Pediatr Dev Pathol. 2011;14(2):111-6.

16. Putra J, Ornvold K. Undifferentiated embryonal sarcoma of the liver: a concise review. Arch Pathol Lab Med. 2015;139(2):269-73.

17. Shi Y, Rojas Y, Zhang W, Beierle EA, Doski JJ, Goldfarb M, et al. Characteristics and outcomes in children with undifferentiated embryonal sarcoma of the liver: a report from the national cancer database. Pediatr Blood Cancer. 2017;64(4):e26272

18. Lin JM, Heath JE, Twaddell WS, Castellani RJ. Undifferentiated sarcoma of the liver: a case study of an erythropoietin-secreting tumor. Int J Surg Pathol. 2014;22(6):555-8

19. Mathias MD, Ambati SR, Chou AJ, Slotkin EK, Wexler LH, Meyers PA, et al. A single-center experience with undifferentiated embryonal sarcoma of the liver. Pediatr Blood Cancer. 2016;63(12):2246-8.

20. May LT, Wang M, Albano E, Garrington T, Dishop M, Macy ME. Undifferentiated sarcoma of the liver: a single institution experience using a uniform treatment approach. J Pediatr Hematol Oncol. 2012;34(3):e114-6.

21. Habibzadeh P, Honarvar B, Silawi M, Bahramjahan S, Kazemi A, Faghihi MA, et al. Association between rs2303861 polymorphism in CD82 gene and non-alcoholic fatty liver disease: a preliminary case-control study. Croat Med J. 2019:60(4):361-8. 
22. Kiani B, Ferrell LD, Qualman S, Frankel WL. Immunohistochemical analysis of embryonal sarcoma of the liver. Appl Immunohistochem Mol Morphol. 2006;14(2):193-7.

23. Zheng JM, Tao X, Xu AM, Chen XF, Wu MC, Zhang SH. Primary and recurrent embryonal sarcoma of the liver: clinicopathological and immunohistochemical analysis. Histopathology. 2007;51(2):195-203.

24. Levy M, Trivedi A, Zhang J, Miles L, Mattis AN, Kim GE, et al. Expression of glypican-3 in undifferentiated embryonal sarcoma and mesenchymal hamartoma of the liver. Hum Pathol. 2012;43(5):695-701.

25. Cook JR, Pfeifer JD, Dehner LP. Mesenchymal hamartoma of the liver in the adult: association with distinct clinical features and histological changes. Hum Pathol. 2002;33(9):893-8.

26. Yesim G, Gupse T, Zafer U, Ahmet A. Mesenchymal hamartoma of the liver in adulthood: immunohistochemical profiles, clinical and histopathological features in two patients. J Hepato-Biliary-Pancreat Surg. 2005:12(6):502-7.

27. Ramanujam TM, Ramesh JC, Goh DW, Wong KT, Ariffin WA, Kumar G, et al. Malignant transformation of mesenchymal hamartoma of the liver: case report and review of the literature. J Pediatr Surg. 1999;34(11):1684-6.

28. Corbally MT, Spitz L. Malignant potential of mesenchymal hamartoma: an unrecognised risk. Pediatr Surg Int. 1992;7(4):321-2.

29. Akinleye A, Rasool Z. Immune checkpoint inhibitors of PD-L1 as cancer therapeutics. J Hematol Oncol. 2019;12(1):92

30. Yasuda T, Perry KD, Nelson M, Bui MM, Nasir A, Goldschmidt R, et al. Alveolar rhabdomyosarcoma of the head and neck region in older adults: genetic characterization and a review of the literature. Hum Pathol. 2009; 40(3):341-8.

31. Olsen SH, Thomas DG, Lucas DR. Cluster analysis of immunohistochemical profiles in synovial sarcoma, malignant peripheral nerve sheath tumor, and Ewing sarcoma. Mod Pathol. 2006;19(5):659-68.

32. Crossland DL, Denning WL, Ang S, Olivares S, Mi T, Switzer K, et al. Antitumor activity of CD56-chimeric antigen receptor T cells in neuroblastoma and SCLC models. Oncogene. 2018;37(27):3686-97.

33. Ng K, Mogul DB. Pediatric liver tumors. Clin Liver Dis. 2018;22(4):753-72.

34. Zynger DL, Gupta A, Luan C, Chou PM, Yang GY, Yang XJ. Expression of glypican 3 in hepatoblastoma: an immunohistochemical study of 65 cases. Hum Pathol. 2008;39(2):224-30.

35. Yamauchi N, Watanabe A, Hishinuma M, Ohashi K, Midorikawa Y, Morishita $\mathrm{Y}$, et al. The glypican 3 oncofetal protein is a promising diagnostic marker for hepatocellular carcinoma. Mod Pathol. 2005;18(12):1591-8.

36. Yan BC, Gong C, Song J, Krausz T, Tretiakova M, Hyjek E, et al. Arginase-1: a new immunohistochemical marker of hepatocytes and hepatocellular neoplasms. Am J Surg Pathol. 2010;34(8):1147-54.

37. Sebire NJ, Malone M. Myogenin and MyoD1 expression in paediatric rhabdomyosarcomas. J Clin Pathol. 2003;56(6):412-6.

38. Wang ZB, Yuan J, Chen W, Wei LX. Transcription factor ERG is a specific and sensitive diagnostic marker for hepatic angiosarcoma. World J Gastroenterol. 2014;20(13):3672-9.

\section{Publisher's Note}

Springer Nature remains neutral with regard to jurisdictional claims in published maps and institutional affiliations.

\section{Ready to submit your research? Choose BMC and benefit from:}

- fast, convenient online submission

- thorough peer review by experienced researchers in your field

- rapid publication on acceptance

- support for research data, including large and complex data types

- gold Open Access which fosters wider collaboration and increased citations

- maximum visibility for your research: over $100 \mathrm{M}$ website views per year

At $\mathrm{BMC}$, research is always in progress.

Learn more biomedcentral.com/submissions 